\title{
FATORES INFLUENCIADORES DA INOVAÇÃO EM BIBLIOTECAS PÚBLICAS ACADÊMICAS
}

\author{
Keila Fernanda de Souza Cruz \\ Mestrado profissional em Gestão de Organizações e Sistemas Públicos \\ Universidade Federal de São Carlos - UFSCAR \\ keilafsc@yahoo.com.br
}

Glauco Henrique de Sousa Mendes

Orientador

Doutor em Engenharia de Produção

Professor do PPGEP - UFSCar e do PPGOSP - UFSCar

\section{Resumo}

Para que as bibliotecas acadêmicas permaneçam relevantes para seus usuários e possam cumprir suas funções como centros de informação nas Universidades, elas precisam inovar para criar serviços que atendam a essas necessidades. A inovação permite que bibliotecas criem novos serviços ou melhorem os serviços já existentes para a sua comunidade de usuários. No entanto, a inovação é um processo complexo e diversos fatores podem influenciar ou inibir o processo de inovação em bibliotecas. Este trabalho tem o objetivo de caracterizar as inovações desenvolvidas pelas bibliotecas acadêmicas (pertencentes às universidades federais e estaduais no Brasil) e os fatores que as influenciam. Deste modo, buscou-se identificar os fatores antecedentes e os consequentes da inovação em bibliotecas. Para consecução dos objetivos, adotou-se a pesquisa de levantamento do tipo survey (abordagem quantitativa). A execução foi realizada em três etapas: i) a pesquisa bibliográfica para a fundamentação teórica; ii) a pesquisa de levantamento para a coleta de dados e iii) tratamento e análise dos dados. Para a coleta dos dados foi aplicado um questionário eletrônico enviado por e-mail para os diretores das bibliotecas de 98 universidades públicas (federais e estaduais). Ao final, obteve-se uma amostra composta de 151 respondentes. Os resultados possibilitaram caracterizar as inovações desenvolvidas pelas bibliotecas. Apesar de criação de serviços inovadores, a maioria das bibliotecas implementa pequenas adaptações e versões melhoradas nos serviços existentes, indicando a predominância de inovações incrementais. Quanto aos fatores influenciadores: Liderança, Cultura e Clima, o Papel dos Servidores e a Cocriação são importantes antecedentes da inovação em bibliotecas. Por outro lado, fatores como processo e recursos possuem uma influência menor. Os resultados também indicam que a cocriação, principalmente dos servidores de linha de frente, é uma importante preditora da inovação. Gestores de bibliotecas podem utilizar os achados da pesquisa para aumentar a eficácia dos processos de inovação. Como consequência, os resultados indicam a contribuição das inovações na melhoria da imagem e satisfação dos usuários das bibliotecas.

Palavras-chave: Inovação. Inovação em Serviços. Cocriação. Biblioteca Acadêmica. 